\title{
Isolation and Characterization of Larvicidal Extracellular Polysaccharide (EPS) from Pseudomonas aeruginosa B01
}

\author{
N. Benit* and A. Stella Roslin \\ Department of Botany, Holy Cross College (Autonomous), Nagercoil, Tamilnadu, India \\ *Corresponding author
}

\begin{tabular}{|l|}
\hline Ke y w o r d s \\
Pseudomonas \\
aeruginosa, \\
$\begin{array}{l}\text { Extracellular } \\
\text { polysaccharides, } \\
\text { Larvicidal activity }\end{array}$ \\
\hline Article Info \\
\hline $\begin{array}{l}\text { Accepted: } \\
\text { 04 December } 2017 \\
\text { Available Online: } \\
\text { 10 January } 2018\end{array}$ \\
\hline
\end{tabular}

\section{A B S T R A C T}

In the present study extracellular polysaccharide (EPS) was characterized from Pseudomonas aeruginosa B01. EPS was purified using ethanol precipitation and dialysis. The purified EPS from P. aeruginosa B01 was analyzed using a High Performance Liquid Chromatography (HPLC). The infrared spectra of EPS from $P$. aeruginosa B01 clearly showed the presence of carboxylate groups. The FT-IR spectrum indicated an intense absorption band in the region of $3296 \mathrm{~cm}^{-1}$ on the stretching vibration of hydroxyl groups $(\mathrm{OH})$. The bands in the region of $2941 \mathrm{~cm}^{-1}$ and $1627 \mathrm{~cm}^{-1}$ are due to stretching vibrations of $\mathrm{C}-\mathrm{H}$ bonds. The absorption in the region of $1029.99 \mathrm{~cm}^{-1}$ indicated the presence of glycoside link in the alpha $(\alpha)$ conformation. A $\mathrm{C}=\mathrm{O}$ stretch between at 1730 and 1700 indicated the presence of carboxylic acid group. The monosaccharide composition of hydrolyzed EPS was analyzed using Gas Chromatography - Mass Spectrophotometry (GC-MS). GC-MS analysis revealed the presence Octasiloxane, 1, 1, 3, 3, 5, 5, 7, 7, 9, 9, 11, 11, 13, 13, 15, 15 - Hexadecamethyl, D-mannose, N-Hexadecanoic acid, Cyclohexane, 1-(1,5, Dimethylhexyl)4-(4-methylpentyl)-, D-galactose, Cyclotrisiloxane, hexamethyl-, and D-glucose were detected. Nuclear Magnetic Resonance (NMR) spectrum of EPS from $P$. aeruginosa $\mathrm{B} 01$ revealed two peak signals at $3.6 \mathrm{ppm}$ and $6 \mathrm{ppm}$. The ${ }^{1} \mathrm{H}$ NMR spectrum of EPS from $P$. aeruginosa B01 showed that protons appeared at 6.131, 6.113, $6.096,6.078,3.651,3.633$ and $3.615 \mathrm{ppm}$. The anomeric protons of residues and their chemical shift at these ppm suggest these residues are $\alpha$ and $\beta$ linked. Although, NMR peaks are poorly resolved because of viscosity, the characteristic signals for glucan (a branched polysaccharide chain with either 1, 4 or 1, 3 and 1, 6 linkage) anomeric protons could be detected. The ${ }^{1} \mathrm{H}$ NMR spectra of EPS extracted from P. aeruginosa B01 exhibited characteristic chemical shifts (ppm) and corresponding functional groups. Acid hydrolysis of EPS was carried out using $\mathrm{H}_{2} \mathrm{SO}_{4}$ and yielded hydrolyzed product of polysaccharide monomers. The purified EPS showed potent activity against mosquito larvae.

\section{Introduction}

Bacterial polysaccharides represent a diverse range of macromolecules that include capsular polysaccharides, extracellular polysaccharides (EPS) and peptidoglycan (Poli et al., 2008). The structure and the function of these polysaccharides varied widely. The EPS is 
highly hydrated, gel-like and charged matrix. The EPS mainly consists of lipids, proteins, extracellular DNA and polysaccharides (Flemming et al., 2007). Recently, more attention has been paid in exploring EPS from many sources because of their applications in various industries. The wide physical and structural diversity and other properties of EPS produced by the biofilm-forming bacteria make it biotechnologically and industrially significant (Vu et al., 2009).

EPSs are secreted by various microorganisms such as, bacteria, fungi, blue-green algae and macro algae (Amjres et al., 2014). Bacterial species such as, Vibrio parahaemolyticus (Muralidharan and Jayachandran, 2003), V. harveyi (Bramhachari and Dubey, 2006), V. alginolyticus (Bramhachari et al., 2007), Oenococcus oeni I4 (Ibarburu et al., 2007) V. furnissii (Kavita et al., 2011), Pediococcus parvulus (Duenas-Chasco et al., 1997), Lactobacillus sp. G77 (Dueñas-Chasco et al., 1998), Lactobacillus (Costa et al., 2010), Pediococcus sp. (Ramchandran and Shah, 2010), Lactococcus (Song et al., 2013), Bifidobacterium (Zhang et al., 2013), Cordyceps gracilis (Grev.) (Sharma et al., 2015), Bacillus sp. (Orsod et al., 2012) was reported to produce EPSs.

Some of the microbial EPS can replace polysaccharides extracted from plants for example pectin or guar gum, or alginate, or carrageenan extracted from algae in traditional applications, due to their physical properties. The microbial EPS possesses superior and unique properties that enable the development of new commercial entities (Freitas et al., 2011). Because of this reason, in recent years, there has been an increasing demand for the isolation and identification of new microbial polysaccharides that can compete with traditional polymers because of their improved chemical and physical properties, higher flocculating and emulsifying activities, biological activity and resistance to solvents (Kumar et al., 2007). In addition, microbial polysaccharides production is more advantageous comparing with algae-derived and plant polysaccharides, because usually its productivity is high in control product composition, productivity and yield (Moreno et al., 1998).

Microbial polysaccharides have pesticidal activities. Over the past few decades, chemical pesticides were widely used in agricultural practices. However, the widespread and prolonged use of these chemical pesticides resulted in biomagnifications of insecticides and insecticide resistance, which in turn resulted baring on export of agricultural products. It was estimated that the damage to the social economy and environment was caused by chemical pesticides about $\$ 8.1$ billion a year (Shen and Zhang, 2000). Further, the use of organic insecticides in pest control programs in agricultural crop throughout the world had caused major damage to the environment, pest resistance to insecticides, pest resurgence, and lethal effects on non-target organisms (Abudulai et al., 2001). The main advantages of biopesticides are less harmful, designed to affect only one specific pest, very effective in very small quantities, degrade quickly and very less pollution. In this study, an attempt was made to characterize EPS from $P$. aeruginosa B01.

\section{Materials and Methods}

\section{Isolation of EPS producing bacterial isolate}

EPS producing bacterial isolates were isolated from the Municipal wastewater. A total of one $\mathrm{ml}$ of sewage water was aseptically added in physiological saline $(0.9 \% \mathrm{NaCl})$ and serial dilutions were made upto $10^{-7}$ and incubated in nutrient agar medium (Himedia, Mumbai, India). Bacteria that produce EPS characterized by colonies of bacteria that form 
very thick slime subsequently were selected and purified by streaking the four quadrants to obtain single colonies (Fusconi and Godinho, 2002).

\section{Characterization of EPS producing bacteria}

Based on the morphological, biochemical tests and 16S rRNA analysis, the bacterial isolates were identified. Gram staining, motility test, indole production, starch-, gelatin-, casein hydrolysis, hydrogen sulphide production, urease-, citrate utilization, nitrate reduction, catalase test, oxidase and o fermentation test were carried out (Holt et al., 1994). The bacterial isolate was further subjected for $16 \mathrm{~S}$ rRNA sequencing.

The universal primer (P1: 5'AGAGTTTGATCMTGGCT AG-3' (forward) and P2: 5'-ACGGGCGGTGTGTRC-3' (reverse) was used to amplify the $16 \mathrm{~S}$ rRNA. DNA was amplified by using a Thermal Cycler with DNA polymerase enzyme (Sigma-Aldrich, USA). The amplified PCR product was purified by standard method and sequenced. Sequence comparison with databases was performed using BLAST through the NCBI server (Altschul et al., 1997). The sequence was submitted to the GenBank database and an accession number was assigned.

\section{Inoculum preparation}

The candidate organism, $P$. aeruginosa B01 was inoculated into the nutrient broth medium composed of $(\mathrm{g} / \mathrm{l})$ peptone digest of animal tissue 5.0, sodium chloride 5.0, beef extract 1.5, and yeast extract 1.5. The medium $\mathrm{pH}$ was adjusted to 7.0. Then, the Erlenmeyer flask was inoculated with a loopful culture of $P$. aeruginosa $\mathrm{B} 01$ and incubated at $37{ }^{\circ} \mathrm{C}$ for $18 \mathrm{~h}$. It was stored at $2-8{ }^{\circ} \mathrm{C}$ and used as the inoculum for further studies.

\section{Production and extraction of EPS}

EPS production was performed in culture containing nutrient broth medium. The potent EPS producing bacterial isolate was incubated at $37{ }^{\circ} \mathrm{C}$ for 5 days. EPS was precipitated from the cell free extract by adding double volumes of ice cold ethanol. The mixture was kept in ice for $2 \mathrm{~h}$ and the precipitate was collected by centrifugation $\left(10,000 \mathrm{rpm}, 15 \mathrm{~min}, 4{ }^{\circ} \mathrm{C}\right)$. It was partially purified by conducting three successive washes in double distilled water, followed by reprecipitation in ice cold ethanol. The EPS precipitates were dried in an oven at $60 \pm 2{ }^{\circ} \mathrm{C}$ to obtain constant weight. The extracted EPS was quantified using phenolsulphuric acid method (Dubois et al., 1956) and glucose was used as standard.

\section{Purification of EPS from $P$. aeruginosa B01}

This method is mainly based on the elimination of proteins by precipitation with trichloroacetic acid (TCA) (12\%, w/v) and subsequent precipitation of EPS was done by using double volumes of ice cold ethanol. Further, EPS was purified by following the combination of ethanol precipitation and dialysis. Ice cold ethanol was added to supernatant ratio of $3: 1(\mathrm{v} / \mathrm{v})$. The precipitated EPS was further dialyzed against double distilled water with a molecular cut-off weight of 12-14 kDa for $24 \mathrm{~h}$. The sample was then centrifuged at 10,000 rpm for $15 \mathrm{~min}$ and the precipitate was recovered. The precipitated product (EPS) was dried at $40 \pm 2{ }^{\circ} \mathrm{C}$ until a constant weight was obtained. The protein content and carbohydrate content of purified EPS were analyzed.

\section{High Performance Liquid Chromatography (HPLC) analysis}

HPLC analysis was performed to check the purity of the sample. This was performed using a HPLC-system (Cyberlab, U.S.A). The 
mobile phase (acetonitrile and water, 65:35 ratio) and sample were degassed using a Sonicator. $10 \mu \mathrm{l}$ sample was injected on C18 column $(7.8 \times 300 \mathrm{~mm})$ under optimized chromatographic conditions.

\section{Fourier-Transform Infrared (FT-IR) spectroscopy}

FT-IR spectrum of the EPS was measured. The purified EPS was further allowed to dry $12 \mathrm{~h}$ on stainless steel before FT-IR analysis. The sample pellets were prepared by mixing the fine dried EPS (2 mg) with $200 \mathrm{mg} \mathrm{KBr}$. Spectrum was recorded using Shimadzu FTIR spectrophotometer (IR Prestige-21). The FT-IR spectrum was recorded in the region of $4000-500 \mathrm{~cm}^{-1}$ and $\mathrm{KBr}$ pellet was used as a background reference (Mishra and Jha, 2013).

\section{Gas Chromatography - Mass Spectrometry (GC-MS) analysis}

The GC-MS analysis of EPS was carried out using Thermo GC-trace standard non-polar column (Dimension: 30 meters, film: 0.25 $\mu \mathrm{M})$. The injector temperature was set at 260 ${ }^{\circ} \mathrm{C}$ during the chromatographic run.

The $1 \mu$ l of sample was injected into the instrument. The oven temperature was as follows: $60{ }^{\circ} \mathrm{C}(2 \mathrm{~min})$; followed by $300{ }^{\circ} \mathrm{C}$ at the rate of $10{ }^{\circ} \mathrm{C} \mathrm{min}^{-1}$; and $300{ }^{\circ} \mathrm{C}$, where it was held for $6 \mathrm{~min}$. The samples were injected in split mode as 10:1. Mass spectral scan range was set at 50-650 (m/z).

The ionization voltage was $70 \mathrm{eV}$. In this chromatography hydrogen was used as the carrier gas. This column $(30 \mathrm{~m} \times 0.25 \mathrm{~mm})$ was closely fitted to a Perkin Elmer gas chromatography which was equipped with a flame ionization detector. The spectrums of the components were compared with the database of spectrum of known components stored in the GC-MS NIST (2008) library.
Nuclear magnetic resonance (NMR) analysis of EPS

${ }^{1} \mathrm{H}-\mathrm{NMR}$ spectra of the polysaccharide solution was recorded at room temperature (30 $\pm 2{ }^{\circ} \mathrm{C}$ ) using a Bruker Avance II-500 spectrometer. The polysaccharide was dissolved and analyzed in $99.96 \% \quad \mathrm{D}_{2} \mathrm{O}$ yielding a clear solution at $5 \mathrm{mg} / 500 \mu \mathrm{l}$ concentration. Tetramethylsilane (TMS) was used as an internal standard. For ${ }^{1} \mathrm{H}$ NMR spectra, the sample was submitted to a delay (D1) and acquisition time (AQ) of $1.00 \mathrm{~s}$ and $3.17 \mathrm{~s}$ respectively. Chemical shifts were measured in part per million (ppm) with signal of $\mathrm{D}_{2} \mathrm{O}$ as reference.

\section{Acid hydrolysis of EPS}

The purified EPS (0.5 g) was hydrolyzed by adding $1.25 \mathrm{ml}$ of concentrated sulphuric acid $(72 \%)$ and was incubated at $30{ }^{\circ} \mathrm{C}$ for $60 \mathrm{~min}$. To this $13.5 \mathrm{ml}$ of double distilled water was added and kept it in a water bath for $4 \mathrm{~h}$. Then it was cooled and $3.1 \mathrm{ml}$ of $32 \%$ (w/v) sodium hydroxide solution was added. The hydrolyzed sample was dissolved in methanol as described by Vijayabaskar et al., (2011). Finally, the acid hydrolyzed EPS sample was analyzed with a Thin Layer Chromatography (TLC). The mixture of acetic acid: chloroform: ethanol: water (11:3:11:1) was used as the mobile phase. The spots migrated on the TLC plate were detected by spraying with an alcoholic solution of $\alpha$-naphthol and sulphuric acid. Then, the plate was heated at $120{ }^{\circ} \mathrm{C}$ for $3 \mathrm{~min}$. The development of purple colour

\section{Insecticidal properties of EPS}

Purified EPS was used to evaluate the insecticidal properties. For this experiment, the mosquito larvae were collected from the stagnant wastewater. These larvae were counted and distributed 20 numbers each in 
plastic containers. Experiment was carried out by applying $10 \mathrm{mg}$ of EPS/dL water. It was continued upto $96 \mathrm{~h}$ and the mortality rate of the larvae was registered.

\section{Results and Discussion}

EPS was isolated and characterized from various Pseudomonas sp. for eco-friendly applications. The monosaccharides isolated from $P$. aeruginosa $\mathrm{B} 01$ in this study was similar to that of sugar components in $P$. putida G7 (Kachlamy et al., 2001) and in $P$. caryophylli CFR1705 (Sudhamani et al., 2004).

Lipopolysaccharies with phosphate groups have been isolated from various Pseudomonas sp. (Kachlany et al., 2001). In P. fluorescens Biovar II, the EPS consists of fucose, rhamnose, ribose, xylose, arabinose, mannose, glucose, galactose and low level of phosphate and sulphate (Hung et al., 2005). The types of EPS produced by $P$. aeruginosa and B. subtilis were significantly differed each other (Harimawan and Ting, 2016).

\section{Purification of EPS}

Purification of the EPS can be obtained by precipitation with the addition of organic solvents such as ethanol, acetone or ethyl acetate. In the present investigation ethanol was used for the precipitation of EPS. The results obtained in this study were in agreement with the previous results. Recently, Yang et al., (2015) and Bajpai et al., (2016) used ethanol to precipitate EPS from various sources and showed better results than other organic solvents. The EPS of $P$. aeruginosa B01 showed one major and two minor peaks on the HPLC spectrum and these were detected at the retention time of 1.54, 2.12 and $6.18 \mathrm{~min}$, respectively. The height of the major peak was 174, 58 and $65 \mathrm{mv}$, respectively (Fig. 1).

\section{FT-IR spectrum of EPS from $P$. aeruginosa B01}

The infrared spectra of EPS from $P$. aeruginosa B01 clearly showed the presence of carboxylate groups. These carboxylate groups may serve as binding sites for divalent metal ions. The FT-IR spectrum indicated an intense absorption band in the region of 3296 $\mathrm{cm}^{-1}$ on the stretching vibration of hydroxyl groups $(\mathrm{OH})$. The bands in the region of 2941 $\mathrm{cm}^{-1}$ and $1627 \mathrm{~cm}^{-1}$ are due to stretching vibrations of $\mathrm{C}-\mathrm{H}$ bonds. The absorption in the region of $1029.99 \mathrm{~cm}^{-1}$ indicated the presence of glycoside link in the alpha $(\alpha)$ conformation. A $\mathrm{C}=\mathrm{O}$ stretch between at 1730 and 1700 indicated the presence of carboxylic acid group (Fig. 2).

In this study, a vibration peak was detected at $1373 \mathrm{~cm}^{-1}$ and this peak indicated the presence of carboxy groups. The spectrum peak at $3296.35 \mathrm{~cm}^{-1}$ indicated the presence of $\mathrm{OH}$ group and $\mathrm{NH}_{2}$ group in the EPS molecule (Desouky et al., 2008). In this study, a medium-broad $\mathrm{C}=\mathrm{O}$ stretching was observed about $1029 \mathrm{~cm}^{-1}$ due to the ether linkages present within oligomers (Wang et al., 2010). This stretching shows the good flexibility of the chain of EPS as studied by Shingel (2002). The peak between 1200 and $900 \mathrm{~cm}^{-1}$ was mainly attributed to polysaccharide composition of EPS.

The band vibrations at $1627 \mathrm{~cm}^{-1}$ are generally indicative of amide bonds. The stretching vibration of $\mathrm{OH}$ groups in the EPS was described earlier (Liu et al., 2007). The bands in the region of $2941.44 \mathrm{~cm}^{-1}$ were due to stretching vibrations of $\mathrm{C}-\mathrm{H}$ bonds, in accordance with the observations made previously with EPS from various bacterial species (Liu et al., 2007). In EPS analysis using IR spectra, $\beta$-configuration was indication of vibration around $890 \mathrm{~cm}^{-1}$ (Yang et al., 2010). 
Fig.1 High Performance Liquid Chromatography (HPLC) chromatogram of EPS

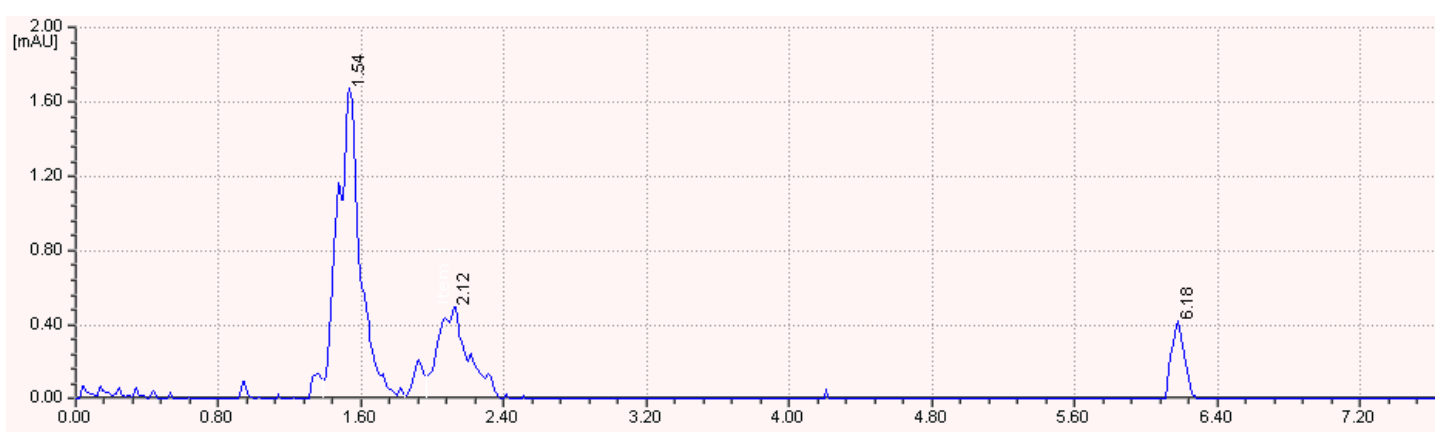

Fig.2 FTIR spectra of extracellular polysaccharide produced by P. aeruginosa B01

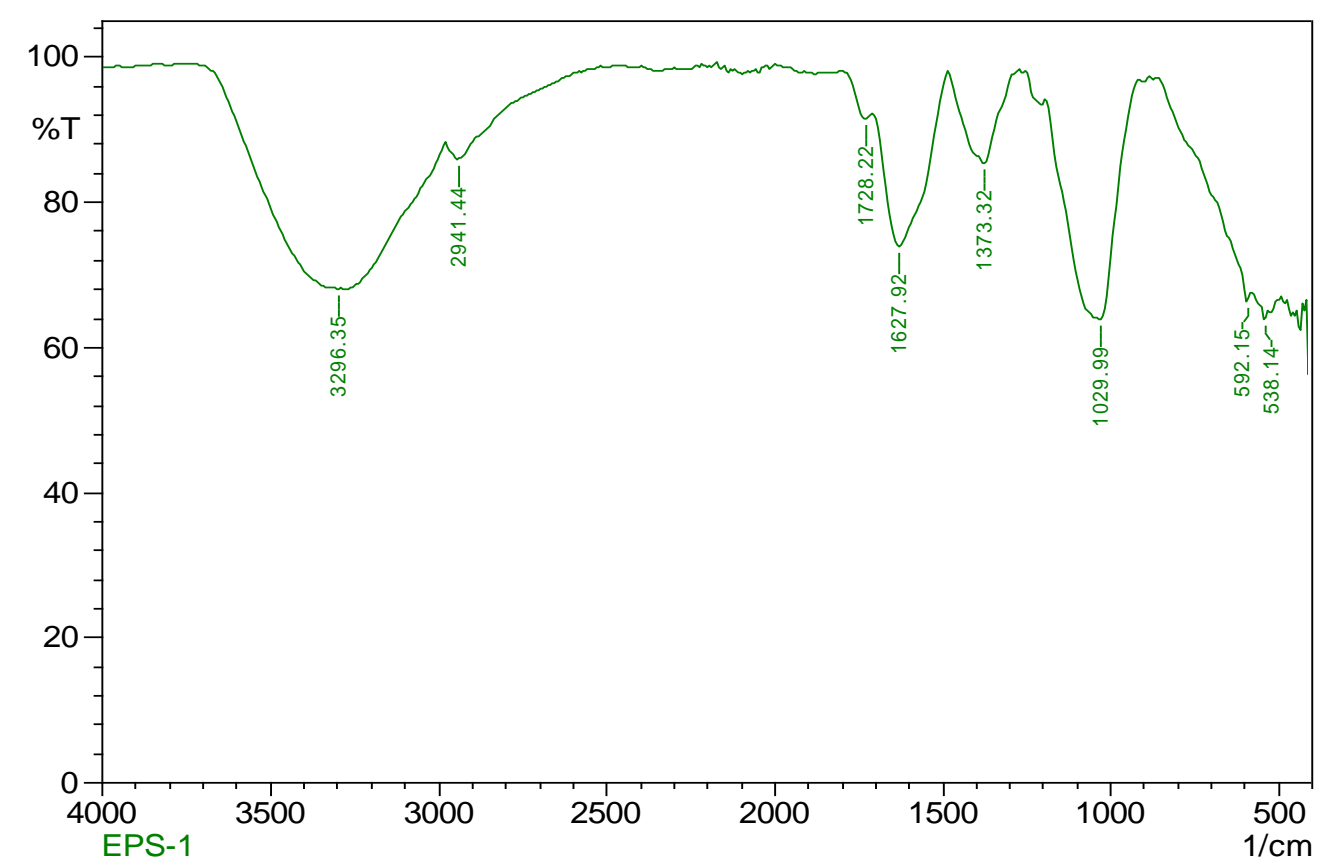

Fig.3 Gas Chromatography - Mass Spectrophotometry profile of EPS obtained from $P$. aeruginosa $\mathrm{B} 01$

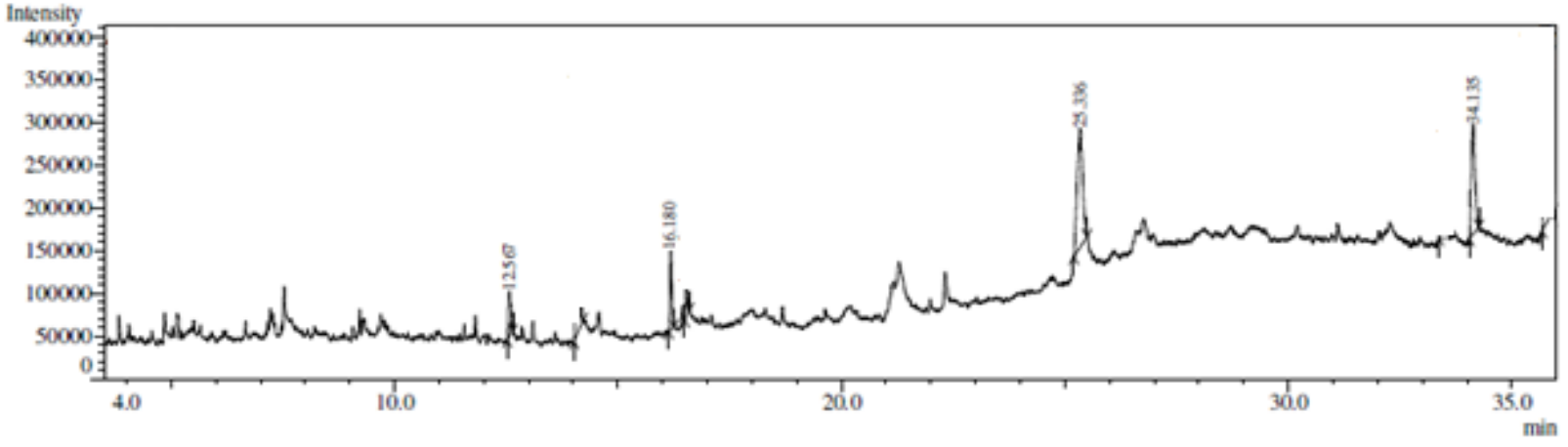


Fig.4 Proton nuclear magnetic resonance $\left({ }^{1} \mathrm{H}\right.$ NMR) spectra of EPS obtained from P. aeruginosa $\mathrm{B} 01$
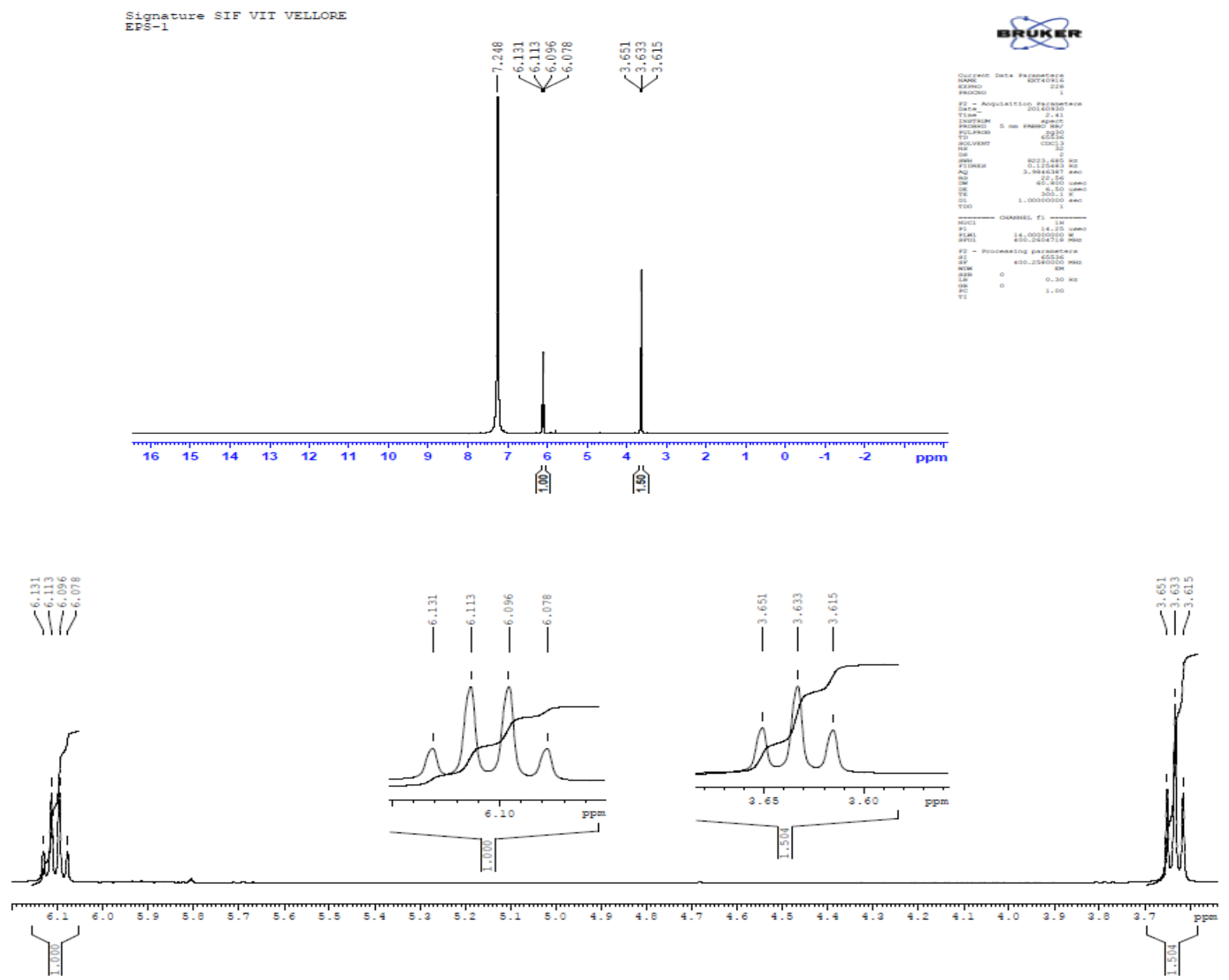

Fig.5 Acid hydrolysed EPS separation using Thin Layer Chromatography [1 - non treated samples; $2-50 \mu \mathrm{g}$ acid hydrolyzed sample; 3 - $75 \mu \mathrm{g}$ acid hydrolyzed sample)

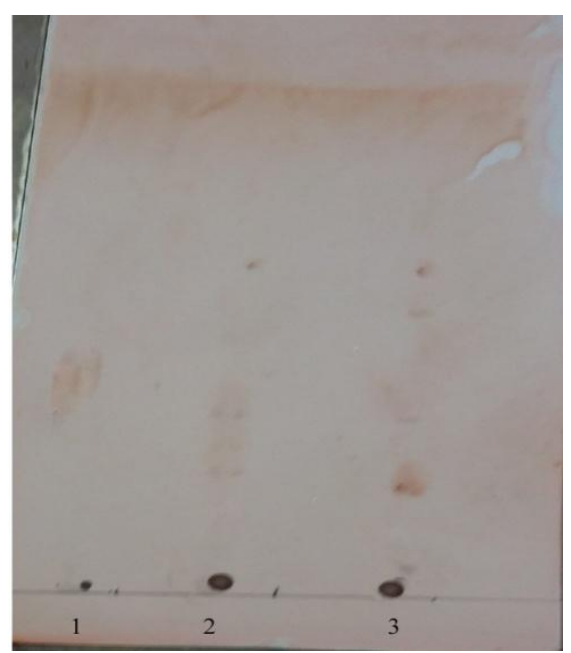


Gas Chromatography - Mass Spectrophotometry (GC- MS) analysis of EPS

The monosaccharide composition of hydrolyzed EPS was analyzed using GC-MS. GC-MS analysis revealed the presence of three monosaccharides and other compounds (Fig. 3). The compounds such as, Octasiloxane, 1, 1, 3, 3, 5, 5, 7, 7, 9, 9, 11, 11, 13, 13, 15, 15 - Hexadecamethyl, mannose, N-Hexadecanoic acid, Cyclohexane, 1-(1,5, Dimethylhexyl)4-(4-methylpentyl)-, galactose, Cyclotrisiloxane, hexamethyl-, and glucose were detected. The multiple combinations of monomeric units along with glucosidic linkages, leading to complex structure of EPS are very difficult to resolve the chemical characteristic features. The linkage pattern of the monomer is evaluated by methylation of all free hydroxyl groups. The combination of EPS from $P$. aeruginosa and $P$. fluorescens was studied by various research groups (Tian, 2008; Torino et al., 2015). Monocarbohydrate constituted exopolysaccharides are often D-galactose, L-fucose, L-rhamnose, D-mannose, N-acetyl- D-glucose amine, Larabinose and $\mathrm{N}$-acetyl-D-galactose amine as well as the uronic acids D-glucuronic acid, Dgalacturonic acid, D-manuronic acid and Lguluronic acid. Other sugar monomers less frequently occurring are D-xylose, D-ribose, 3-keto-deoxy-D-mannooctulosonic acid and several hexoseamineuronic acids (Andersson et al., 2009). In another study, fucose was characterized from the EPS of Enterobacter (Pawlicki-Jullian et al., 2010).

\section{NMR spectrum of EPS from $P$. aeruginosa B01}

In this spectrum two peak signals were detected at $3.6 \mathrm{ppm}$ and $6 \mathrm{ppm}$. The strong water solvent signal was detected at 7.248 ppm. The ${ }^{1} \mathrm{H}$ NMR spectrum of EPS from $P$. aeruginosa $\mathrm{B} 01$ showed that protons appeared at $6.131,6.113,6.096,6.078,3.651,3.633$ and $3.615 \mathrm{ppm}$. The anomeric protons of residues and their chemical shift at these ppm suggest these residues are $\alpha$ and $\beta$ linked. Although, NMR peaks are poorly resolved because of viscosity, the characteristic signals for glucan (a branched polysaccharide chain with either 1,4 or 1,3 and 1, 6 linkage) anomeric protons could be detected. The ${ }^{1} \mathrm{H}$ NMR spectra of EPS extracted from $P$. aeruginosa B01 exhibited characteristic chemical shifts (ppm) and corresponding functional groups. The ${ }^{1} \mathrm{H}$ NMR spectroscopy of the EPS was complex due to the signals in the region of 3.6 to $6.1 \mathrm{ppm}$. Nuclear magnetic resonance (NMR) spectroscopy has been widely used to study the structure of EPS (Cui et al., 2000). The signals obtained in the present study are in agreement with the previous reports. The $\beta-1,6$ glycosidic linkage observed in EPS from $S$. commune AGMJ-1 with spectrum of protons at H1-H6 was $4.25,3.04,3.1,3.2,3.32,4.01 \mathrm{a}$ and $3.61 \mathrm{~b}$. The presence of $\beta$-glucan with $\beta-1-6-$ glycosidic linkage has been reported by Kao et al., (2012) in the polysaccharide isolated from the fruiting body of G. lucidum. Singh et al., (2005) reported that anomeric signals for (1-3)- $\beta$-D-glucan in a ${ }^{1} \mathrm{H}$ NMR spectrum in the liquid state were between 4.7-4.8 and 3.0$3.2 \mathrm{ppm}$, whereas those of (1-6)-D-glucan appear between 4.4 and $4.6 \mathrm{ppm}$. The composition of EPSs produced by Rhizobium was reduced to a few monosaccharides including galactose, mannose, glucose, glucuronic acid, rhamnose, and galacturonic acid (Castellane et al., 2015) (Fig. 4).

\section{Hydrolyed product of EPS from $P$. aeruginosa $\mathrm{B01}$}

In the present study, TLC was used to determine the hydrolyzed product of EPS from $P$. aeruginosa $\mathrm{B} 01$. The composition of EPS varies depending upon several factors, including bacterial strain and kind of metal 
exposure (Aquino and Stuckey, 2008). In the present study, the sugar units such as glucose and galactose were detected from the hydrolysis product of EPS (Fig. 5). This result was in agreement with that of previous reports (Kavita et al., 2013). The EPS of biofilm forming bacterium Aureobasidium pullulans mainly composed of galactose and glucose (Lee et al., 2001). In Lactococcus lactis sub sp. lactis, the sugar units such as rhamnose and fructose were determined (Pan and Mei, 2010) in TLC. The monomers such as galactose and glucose were detected from $L$. fermentum TDS030603 in TLC (Fukuda et al., 2010). In L. rhamnosus JAAS8, the sugar units such as glucose, galactose and $\mathrm{N}$ acetylglucosamine were detected (Yang et al., 2010). The EPS isolated from L. plantarum KF5 composed of glucose, mannose and galactose (Wang et al., 2010).

\section{Insecticidal activity of EPS}

EPS showed insecticidal activity against the mosquito larvae. After $24 \mathrm{~h}$ of incubation, $100 \%$ motality was registered. The bacterial strains such as, Pseudomonas chlororaphis PCL1391 and Pseudomonas protegens strains CHA0 and Pf-5were shown to have insecticidal activity (Ruffner et al., 2013; Péchy-Tarr et al., 2008). Microbial insecticides are the important component of the bio-pesticide industry in recent years (Shi 2000). Xiong et al., (2004) extracted novel compound from Streptomyces sp.173 and showed potent insecticidal activity. The isolated $P$. aeruginosa strain B01 has potent insecticidal activity. This work indicated that micro-organism from wastewater could be an important source of insecticidal EPS.

\section{References}

Abudulai M, Shepard BM, Mitchell PL 2001. Parasitism and predation on eggs of Leptoglossus phyllopus (L.) (Hemiptera:
Coreidae) in Cowpea: Impact of Endosulfan Sprays. J Agric Urban Entomol., 18: 105-115.

Altschul SF, Madden TL, Schaffer AA, Zhang J, Zhang W, Miller et al., 1997. S.F. Gapped BLAST and PSI-BLAST: A new generation of protein database search programs. Nucleic Acids Res., 25: 3389-3402.

Amjres H, Béjar V, Quesada E, Carranza D, Abrini J, Sinquin C., et al., 2014. Characterization of haloglycan, an exopolysaccharide produced by Halomonas stenophila HK30. Int J Biol Macromol., 72: 117-124.

Andersson S, Dalhammar G, Land CJ, Kuttuva Rajarao G 2009. Characterization of extracellular polymeric substances from denitrifying organism Comamonas denitrificans Appl Microbiol Biotechnol., 82: 535543.

Aquino SF, Stuckey DC 2008. Integrated model of the production of soluble microbial products (SMP) and extracellular polymeric substances (EPS) in anaerobic chemostats during transient conditions. Biochem Eng J., 38(2): 138-146.

Bajpail VK, Majumder R, Rather IA, Kim K (2016). Extraction, isolation and purification of exopolysaccharide from lactic acid bacteria using ethanol precipitation method. Bang $J$ Pharmacol., 11: 573-576.

Bramhachari P, Dubey S 2006. Isolation and characterization of exopolysaccharide produced by Vibrio harveyi strain VB23. Lett Appl Microbiol., 43: 571577.

Bramhachari P, Kishor P, Ramadevi R, Kumar R, Rao B, Dubey S 2007. Isolation and characterization of mucous exopolysaccharide (EPS) produced by Vibrio furnissii strain VB0S3. J Microbiol Biotechnol., 17: 
44-51

Castellane TCL, Persona MR, Campanharo JC, Lemos ECM 2015. Production of Exopolysaccharide from Rhizobia with potential biotechnological and bioremediation applications. Int J Biol Macromol., 74: 515-522.

Costa NE, Hannon JA, Guinee TP, Auty MAE, McSweeney PLH, BeresfordTP 2010. Effect of exopolysaccharide produced by isogenic strains of Lactococcus lactis on half-fat Cheddar cheese. J Dairy Sci., 93: 3469-3486.

Cui W, Morrison DC, Silverstein R 2000. Dif ferential tumor necrosis factor alpha expression and release from peritoneal mouse macrophages in vitro in response to proliferating Gram-positive versus Gram-negative bacteria. Infect Immun., 68: 4422-4429.

Desouky AM, Haleem AE, Roda FT, Thourya M, Sidra M, Fatima H 2008. Isolation and characterization of extracellular bioflocculants produced by bacteria isolated from Quatari Ecosystems. Pol J Microbiol., 57: 231-239.

Dubois M, Gilles KA, Hamilton JK, Peters PA, Smith F 1956. Colorimetric method for determination of sugars and related substances. Anal Chem., 28: 350-356.

Dueñas-Chasco MT, Rodríguez-Carvajal MA, Tejero-Mateo P, Espartero JL, IrastorzaIribas A, Gil-Serrano AM 1998. Structural analysis of the exopolysaccharides produced by Lactobacillus spp. G-77. Carbohydr Res., 307: 125-133.

Dueñas-Chasco MT, Rodríguez-Carvajal MA, Tejero-Mateo P, Franco-Rodríguez G, Espartero JL, Irastorza-Iribas A, GilSerrano AM 1997. Structural analysis of the exopolysaccharide produced by Pediococcus damnosus 2.6. Carbohydr Res., 303: 453-458.

Flemming H, Neu T, Wozniak D 2007. The EPS matrix: The "House of Biofilm cells". J Bacteriol., 189: 7945-7947.

Freitas F, Alves VD, Reis MAM 2011. Advances in bacterial exopolysaccharides: from production to biotechnological applications. Trend Biotechnol., 29: 388-398.

Fukuda TY, Rossetto FM, Magalhães E, Bryk FF, Lucareli PR, de Almeida Aparecida Carvalho N 2010. Short-term effects of hip abductors and lateral rotators strengthening in females with patellofemoral pain syndrome: a randomized controlled clinical trial. $J$ Orthop Sports Phys Ther., 40(11): 736742.

Fusconi R, Godinho MJL 2002. Screening for exopolysaccharide - producing bacteria from sub-tropical polluted groundwater. Braz, J Biol., 62(2): 363-369

Harimawan A, PengTing Y 2016. Investigation of extracellular polymeric substances (EPS) properties of $P$. aeruginos $a$ and $B$. subtilis and their role in bacterial adhesion. Colloid Sur B: Biointerface., 146: 459-467.

Holt JG, Krieg NR, Sneath PH, Stanley JJ, Williams ST 1994. Bergey's manual of determinative bacteriology. Williams and Wilkins, Baltimere.

Hung CC, Santschi PH, Gillow JB 2005. Isolation and characterization of extracellular polysaccharides produced by Pseudomonas fluorescens Biovar II. Carbo Polymer., 6: 141-147.

Ibarburu I, Soria-Díaz ME, RodríguezCarvajal MA, Velasco SE, TejeroMateo P, Gil-Serrano AM, Irastorza A, Dueñas MT 2007. Growth and exopolysaccharide (EPS) production by Oenococcus oeni I4 and structural characterization of their EPSs. J Appl Microbiol., 103: 477-486.

Kachlany SC, Levery SB, Kim JS, Reuhs BL, Lion LW, Ghiorse WC 2001. Structure and carbohydrate analysis of the exopolysaccharide capsule of 
Pseudomonas putida G7. Environ Microbiol., 3(12): 774-784.

Kao P, Wang S, Hung W, Liao Y, Lin C, Yang W 2012. Structural characterization and antioxidative activity of low-molecular-weights beta1,3-glucan from the residue of extracted Ganoderma lucidum fruiting bodies. J Biomed Biotechnol., 8: 673764.

Kavita K, Mishra A, Jha B 2011. Isolation and physico-chemical characterisation of extracellular polymeric substances produced by the marine bacterium Vibrio parahaemolyticus. Biofouling, 27: 309-317.

Kavita K, Mishra A, Jha B 2013. Extracellular polymeric substances from two biofilm forming Vibrio species: characterization and applications. Carbohy Polym., 94: 882-888.

Kumar AS, Mody K, Jha B 2007. Bacterial exopolysaccharides: A perception. $J$. Basic Microbiol., 47:103-117.

Lee JH, Kim JH, Zhu IH, et al., 2001. Optimization of conditions for the production of pullulan and high molecular weight pullulan by Aureobasidium pullulans. Biotechnol Lett., 23(10): 817-820.

Liu C, Lin Q, Gao Y, Ye L, Xing Y, Xi T 2007. Characterization and antitumor activity of polysaccharide from Strongylo centrotus nudus eggs. Carbohyd Polym., 67: 313-318.

Mishra A, Jha B 2013. Microbial Exopolysacchrides. In E. Rosenberg, E. F. DeLong, F. Thompson, S. Lory, \& E. Stackebrandt (Eds.), The prokaryotes: Applied bacteriol biotechnol., (4th ed., pp. 179-192). Germany: Springer BerlinHeidelberg.

Moreno J, Vargas MA, Olivares H, Rivas J, Guerrero MG 1998. Exopolysaccharide production by the cyanobacterium Anabaena sp. ATTC 33047 in batch and continuous culture. J Biotechnol., 60: 175- 182.

Muralidharan J, Jayachandran S 2003. Physicochemical analyses of the exopolysaccharides produced by a marine biofouling bacterium, Vibrio alginolyticus. Process Biochem., 38: 841-847.

Pan D, Mei X 2010. Antioxidant activity of an exopolysaccharide purified from Lactococcus lactis subsp. lactis. Carbo Polymer., 80(3): 908-914.

Pawlicki-Jullian N, Courtois B, Pillon M, Lesur D 2010. Exopolysaccharide production by nitrogen-fixing bacteria within nodules of Medicago plants exposed to chronic radiation in the Chernobyl exclusion zone. Res Microbiol., 161: 101-108.

Péchy-Tarr M, Bruck DJ, Maurhofer M, Fischer E, Vogne C, Henkels MD et al., 2008. Molecular analysis of a novel gene cluster encoding an insect toxin in plant-associated strains of Pseudomonas fluorescens. Environ Microbiol., 10: 2368-2386.

Poli A, Anzelmo G, Nicolaus B 2008. Bacterial Exopolysaccharides from Extreme Marine Habitats: Production, Characterization and Biological Activities. Mar. Drugs. 8(6): 1779 1802.

Ramchandran L, Shah NP 2010. Characterization of functional, biochemical and textural properties of synbiotic low-fat fermented milks during refrigerated storage. LWT-Food Sci Technol., 5: 819-827.

Ruffner B, Péchy-Tarr M, Ryffel F, Hoegger $\mathrm{P}$, Obrist C, Rindlisbacher A et al., 2013. Oral insecticidal activity of plantassociated pseudomonads. Environ Microbiol., 15: 751-763.

Sharma SK, Gautam N, Arti NS 2015. Optimization, Composition, and Antioxidant Activities of Exo- and 
Intracellular Polysaccharides in Submerged Culture of Cordyceps gracilis (Grev.) Durieu \& Mont. Evidence-Based Compl Alternat Med., 2015: Article ID 462864, 8 pages

Shen YC, Zhang YB 2000. Biopesticides. Chemical Industry Press, Beijing.

Shi YF 2000. Advances of insecticidical microorganisms. Plant Protect., 26, 3234.

Shingel KI 2002. Determination of structural peculiarities of dextran, pullulan and cirradiated pullulan by Fourier-transform IR spectroscopy. Carbohyd Res., 337: 1445-1451.

Singh S, Kate BN, Banerjee UC 2005. Bioactive compounds from cyanobacteria and microalgae: an overview. Crit Rev Biotechnol., 25: 7395.

Song YR, Jeong DY, Cha YS, Baik SH 2013. Exopolysaccharide producedby Pediococcus acidilactici M76 isolated from the Korean traditional rice wine, Makgeolli. J Microbiol Biotechnol., 23: 681-688.

Sudhamani SR, Tharanathan RN, Prasad MS 2004. Isolation and characterization of an extracellular polysaccharide from Pseudomonas caryophylli CFR 1705. Carbohy Polym., 56: 423-427.

Tian Y 2008. Behaviour of bacterial extracellular polymeric substances from activated sludge: a review. Int J Environ Pollut., 32: 78-89

Torino MI, Valdez GF, Mozzi F 2015.
Biopolymers from lactic acid bacteria. Novel applications in foods and beverages. Front Microbiol., 6: 834.

Vu B, Chen M, Crawford R, Ivanova E 2009. Bacterial extracellular polysaccharides involved in biofilm formation Molecules, 14: 2535-2554.

Wang Y, Li C, Liu P, Ahmed Z, Xiao P, Bai $X$ 2010. Physical characterization of exopolysaccharide produced by Lactobacillus plantarum KF5 isolated from TibetKefir. Carbohy Polym., 82: 895-903.

Xiong L, Li J, Kong F 2004. Streptomyces sp. 173, an insecticidal micro-organism from marine. Lett Appl Microbiol., 2004, 38, 32-37

Yang W. Z., Chen H. L., Gao F. P., Chen M. M., Li X. M., Zhang M. M., et al., 2010. Self-aggregated nanoparticles of cholesterol-modified pullulan conjugate as a novel carrier of mitoxantrone.Curr. Nanosci. 6: 296-306.

Yang Y, Peng Q, Guo Y, Han Y, Xiao H, Zhou Z 2015. Isolation and characterization of dextran produced by Leuconostoc citreum NM105 from manchurian sauerkraut. Carbohy polymer, 133: 365-372.

Zhang L, Liu C, Li D, Zhao Y, Zhang X, Zeng $X$ 2013. Antioxidant activity of an exopolysaccharide isolated from Lactobacillus plantarum C88. Int J Biol Macromol., 54: 270-275

\section{How to cite this article:}

Benit, N. and Stella Roslin, A. 2018. Isolation and Characterization of Larvicidal Extracellular Polysaccharide (EPS) from Pseudomonas aeruginosa B01. Int.J.Curr.Microbiol.App.Sci. 7(01): 109-120. doi: https://doi.org/10.20546/ijcmas.2018.701.013 